\title{
CP VIOLATION WITH ADDITIONAL B DECAYS
}

\author{
Isard Dunietz \\ CERN, Theory Division \\ CH-1211 Geneva 23, Switzerland
}

\begin{abstract}
The observation of CP violation and the clean extraction of the fundamental CKM phases form the subject of this chapter. After reviewing the classic $C P$ eigenmodes, where $C P$ asymmetries are straightforwardly related to the CKM phases, more detailed methods are discussed. They allow the extraction of the phases from many additional modes, which are no longer $\mathrm{CP}$ eigenstates. The methods covered in this review are angular correlations, time-dependent studies of non-CP eigenmodes, isospin analyses, and detailed studies of $B$ modes with a $D^{\circ}$.
\end{abstract}

To be published in "B Decays," edited by S. Stone

CERN-TH-6239/91

October 1991 

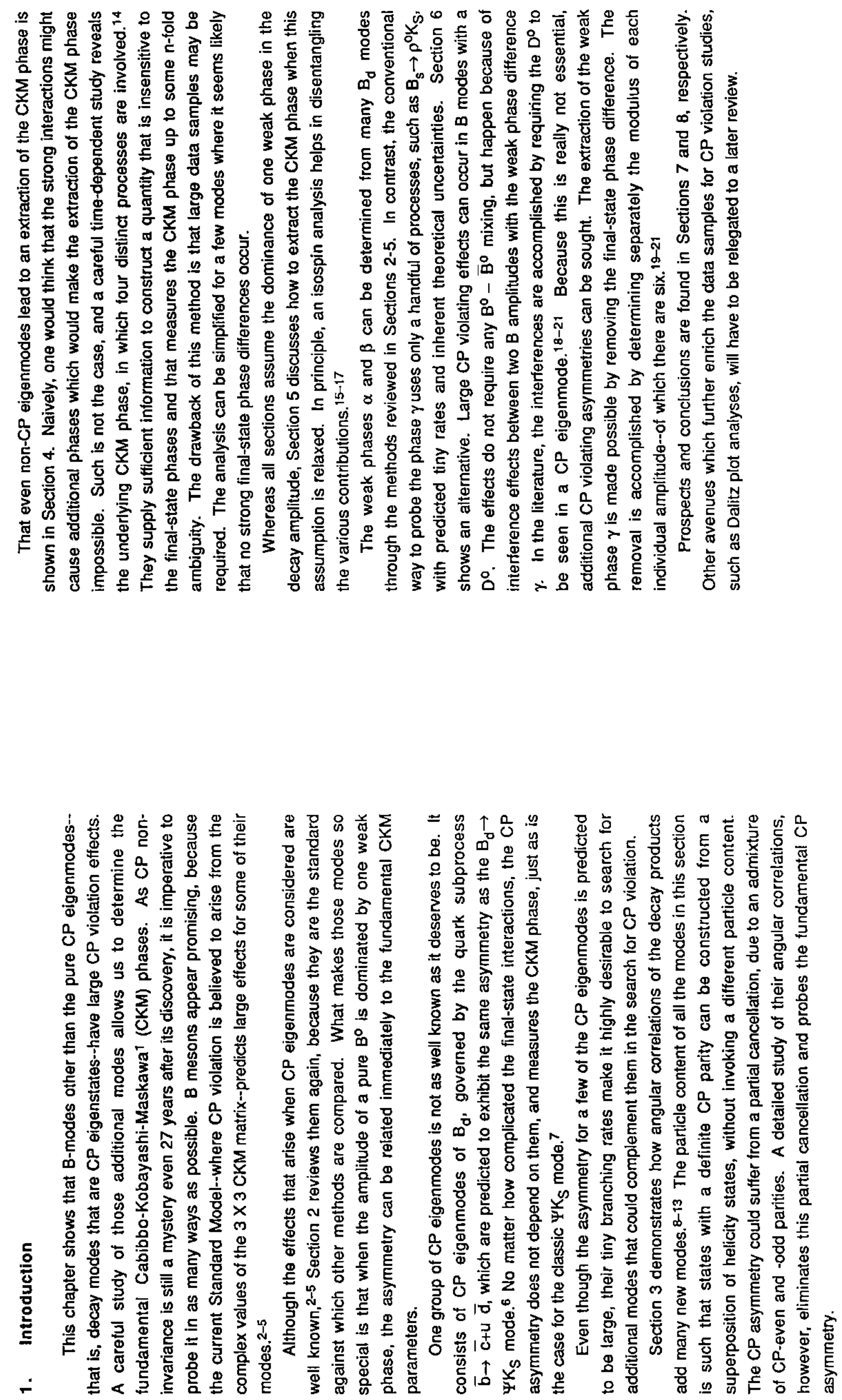

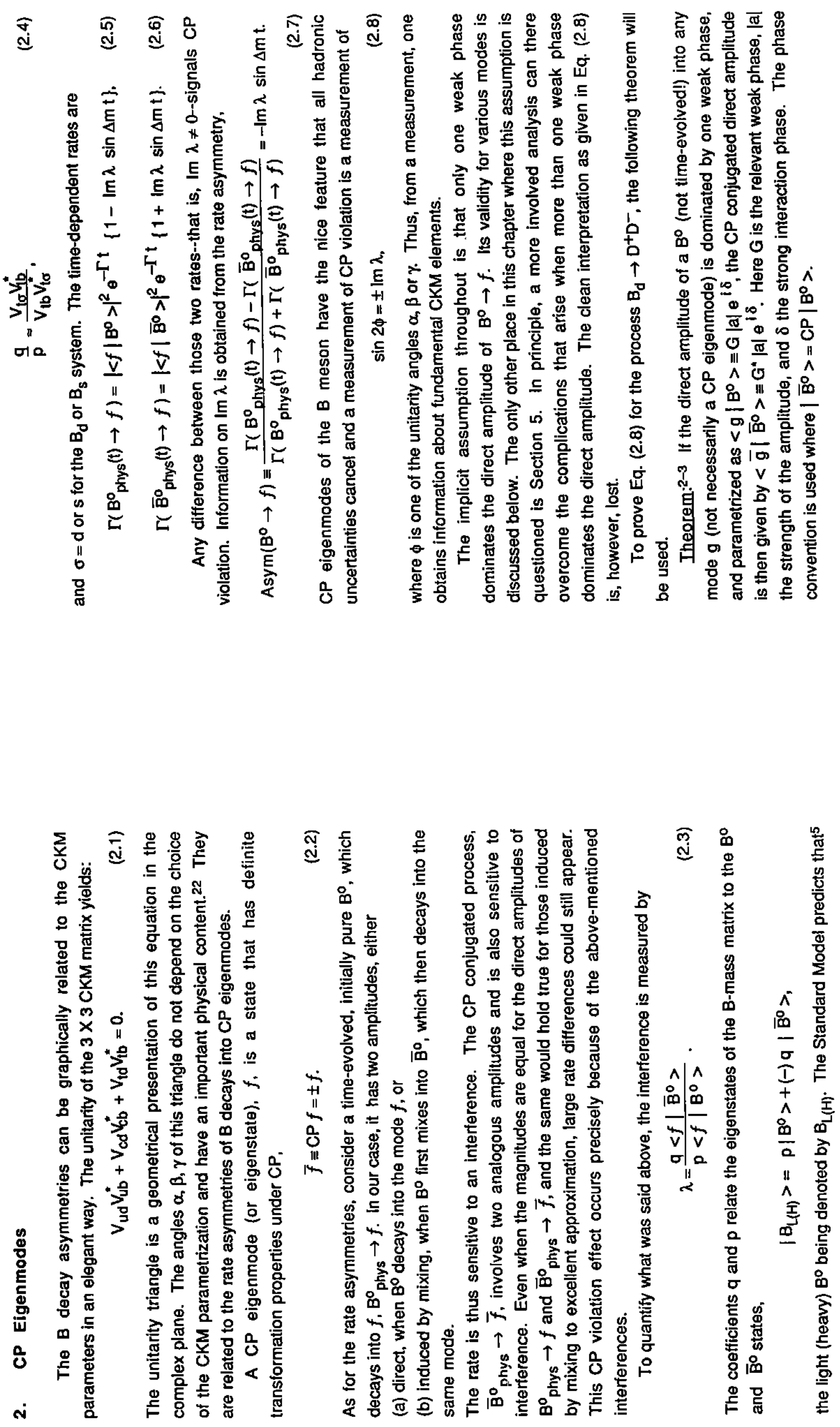

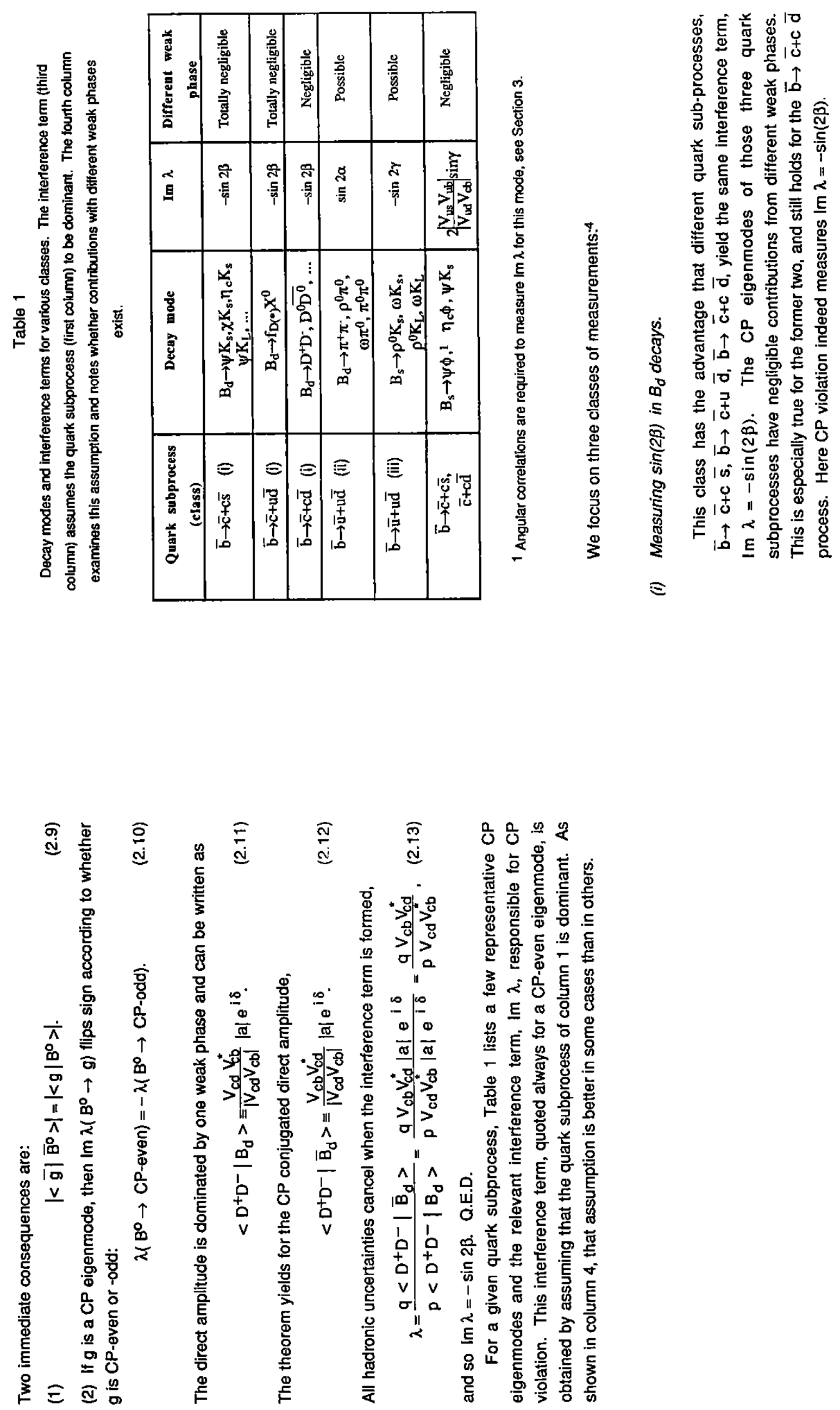

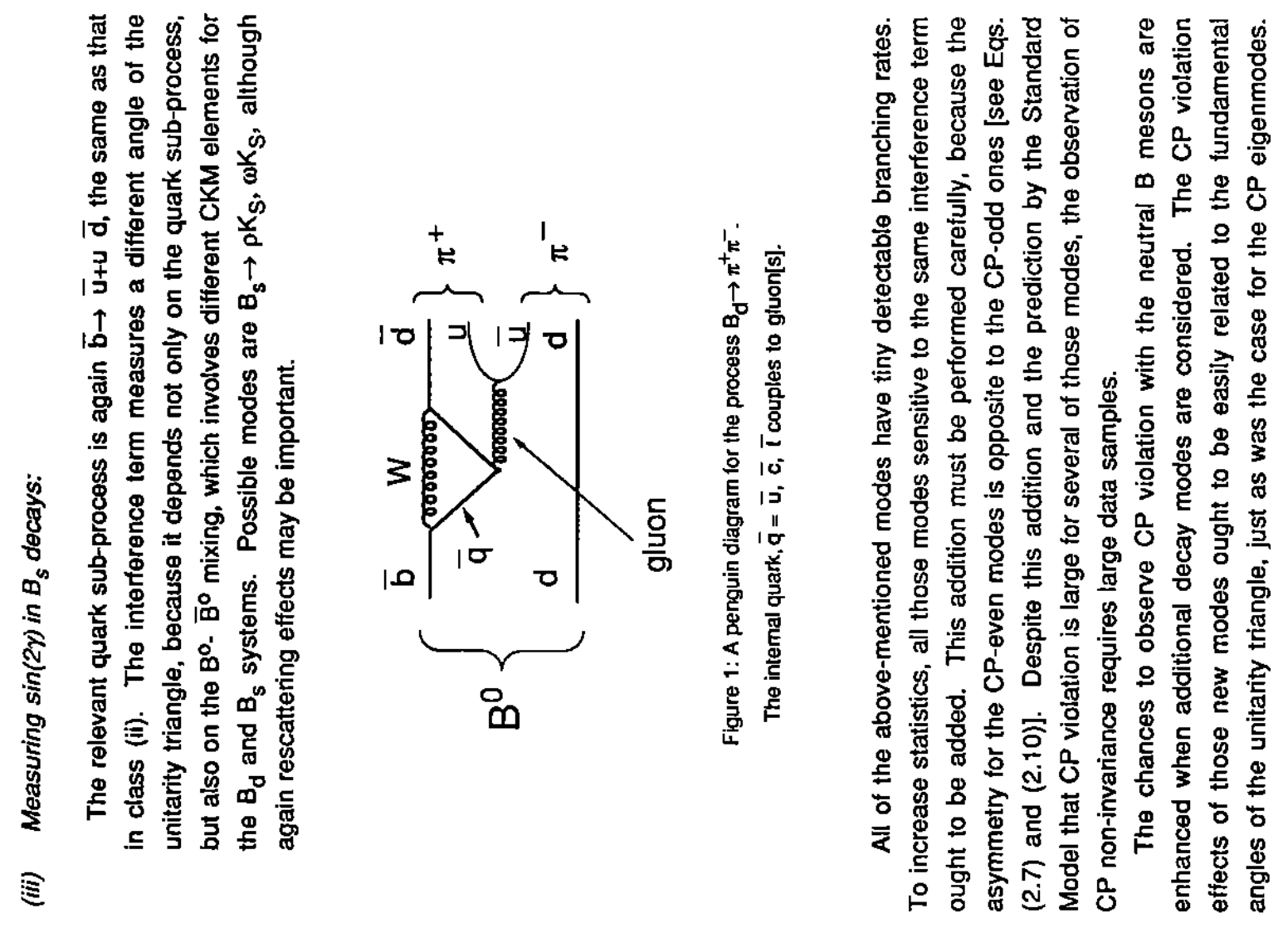

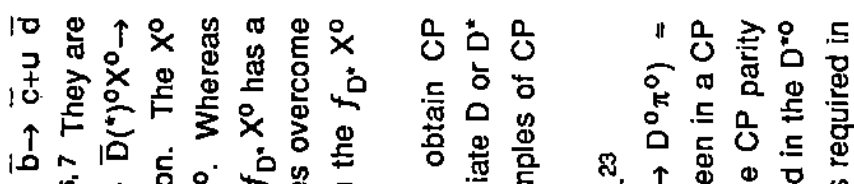

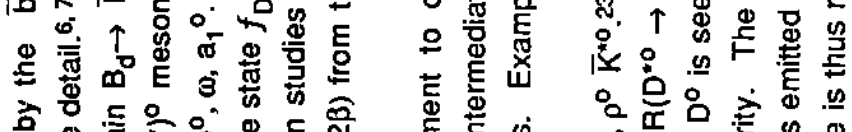

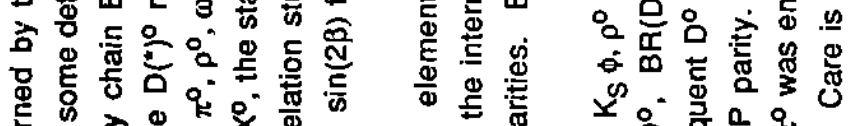

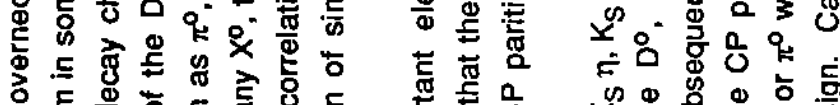

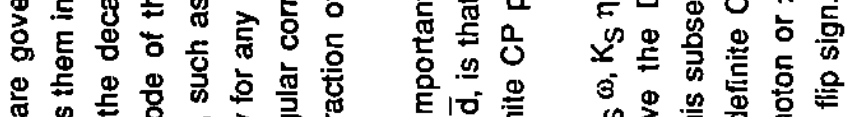

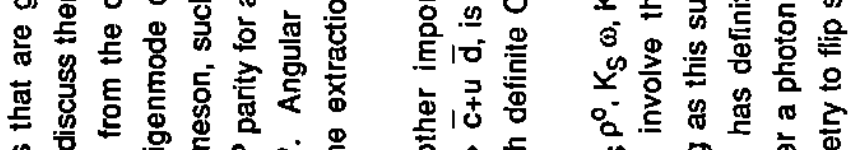

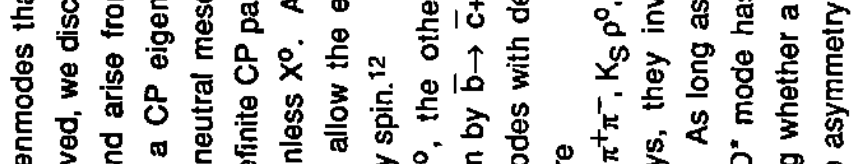

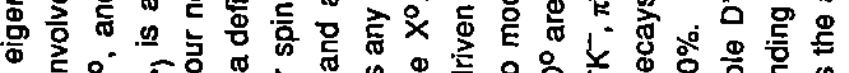

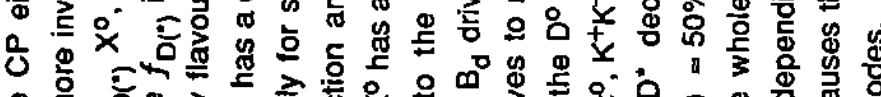

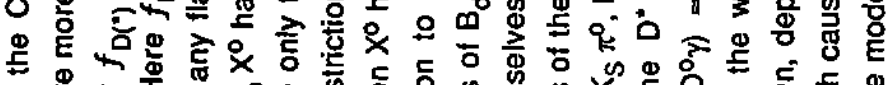

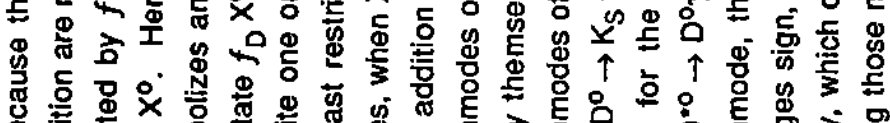

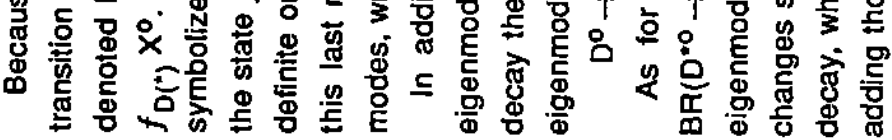



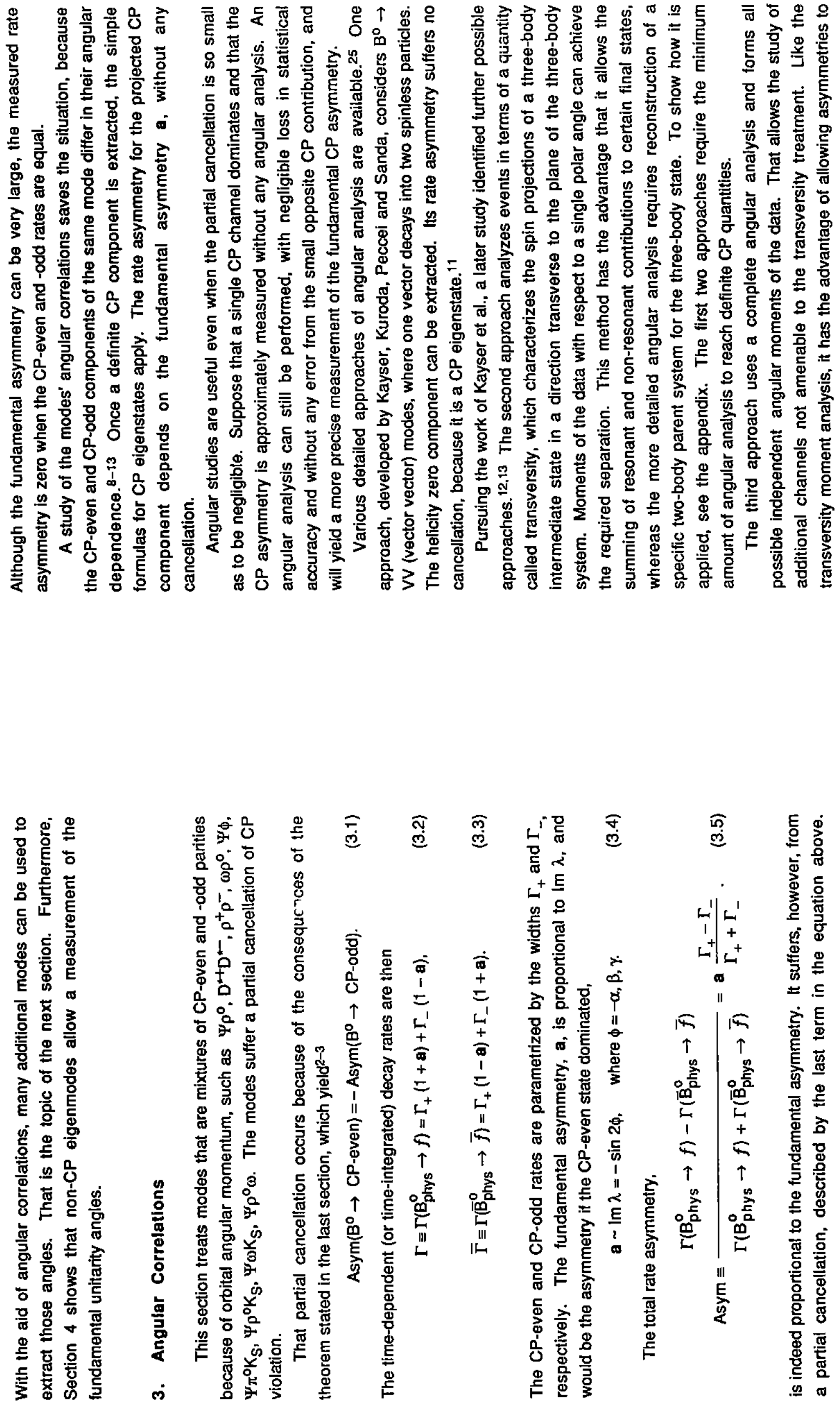


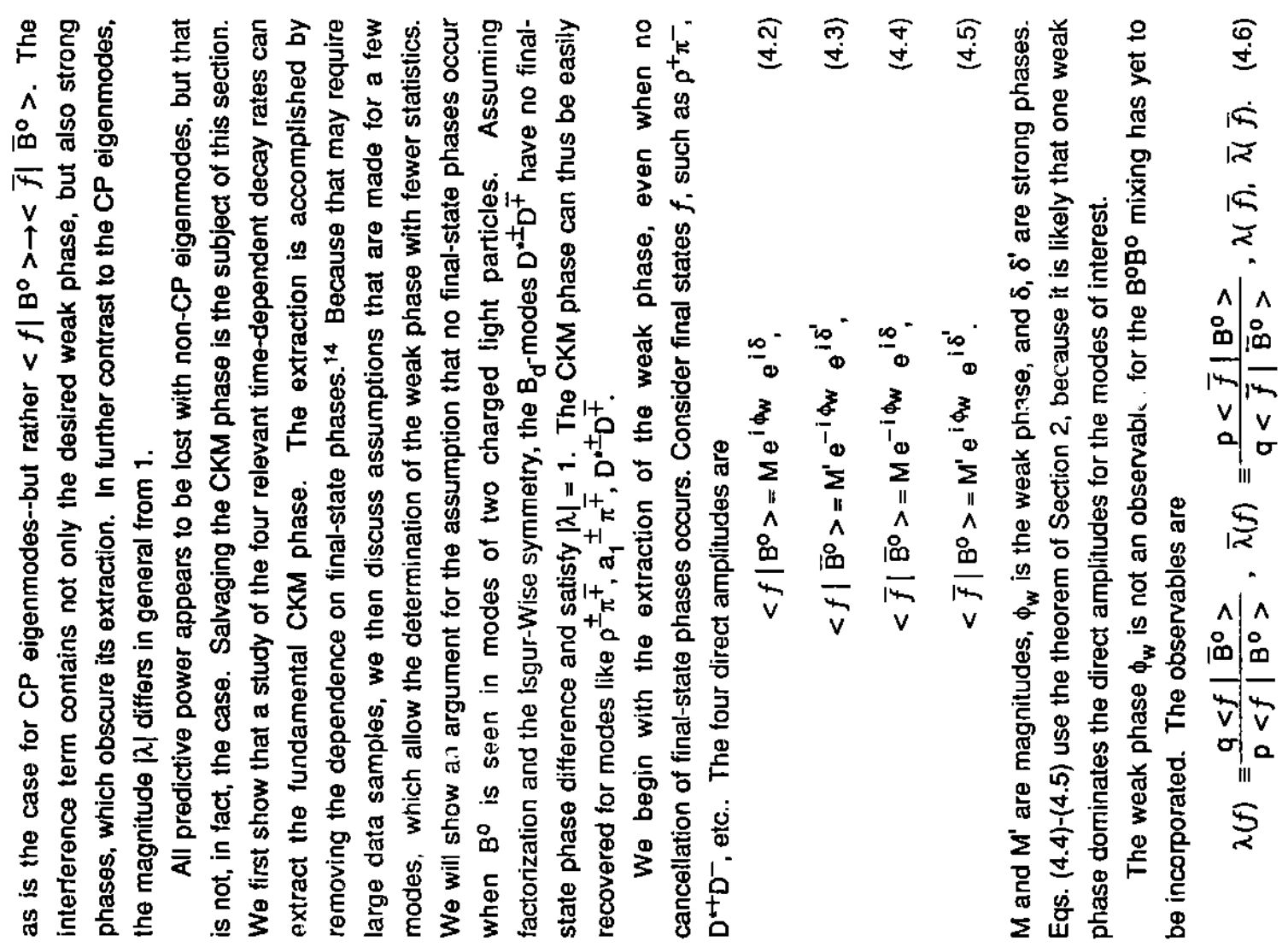

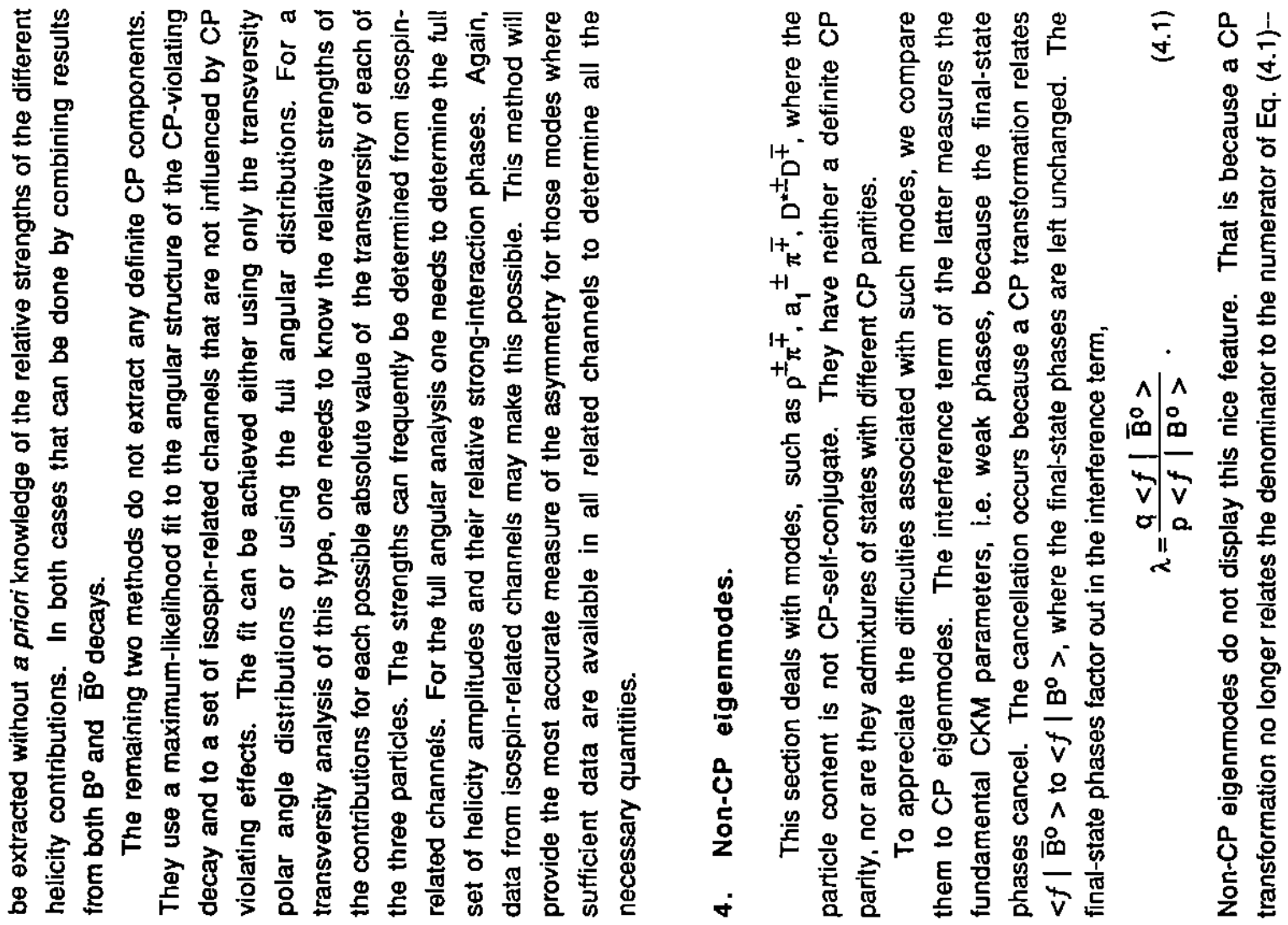



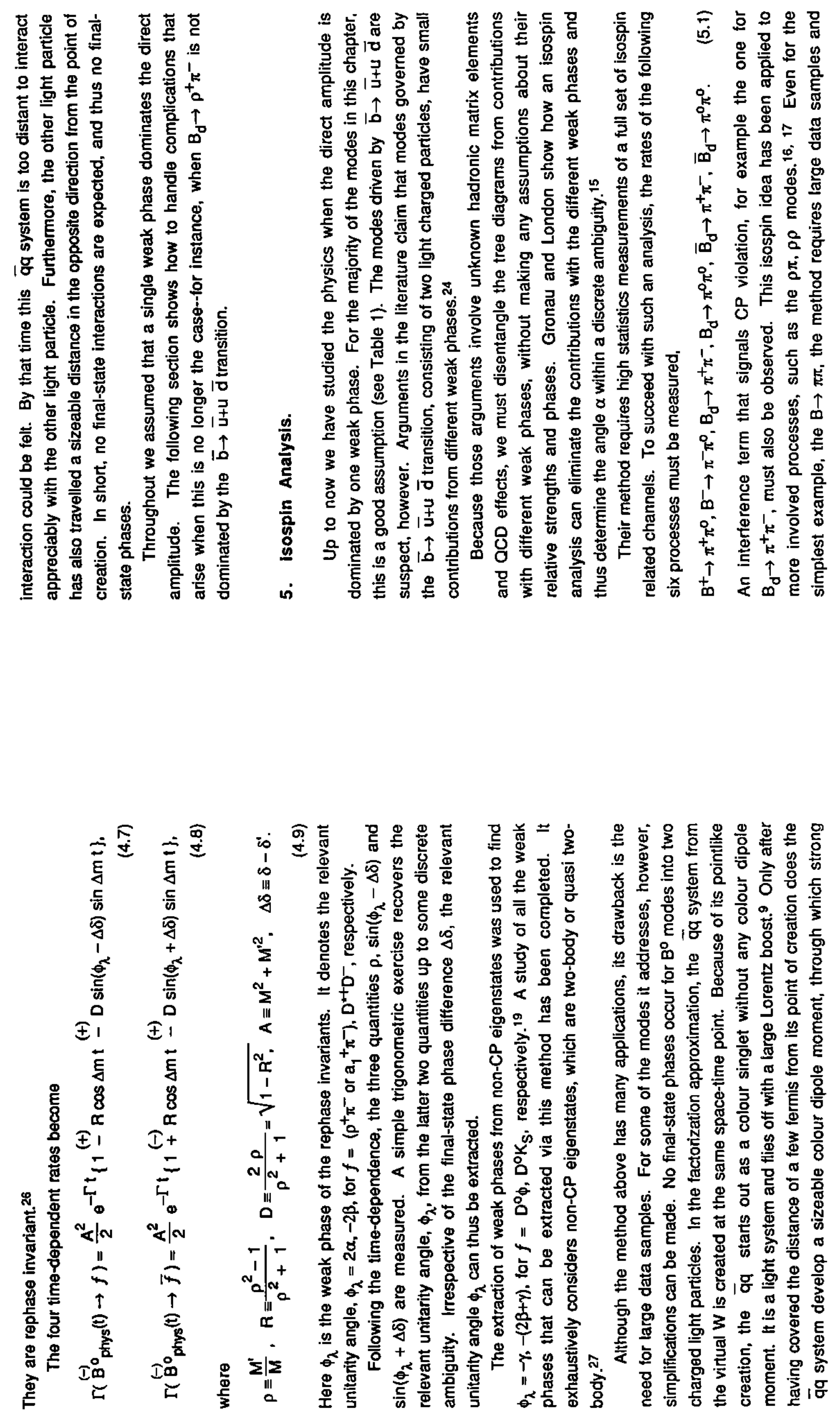

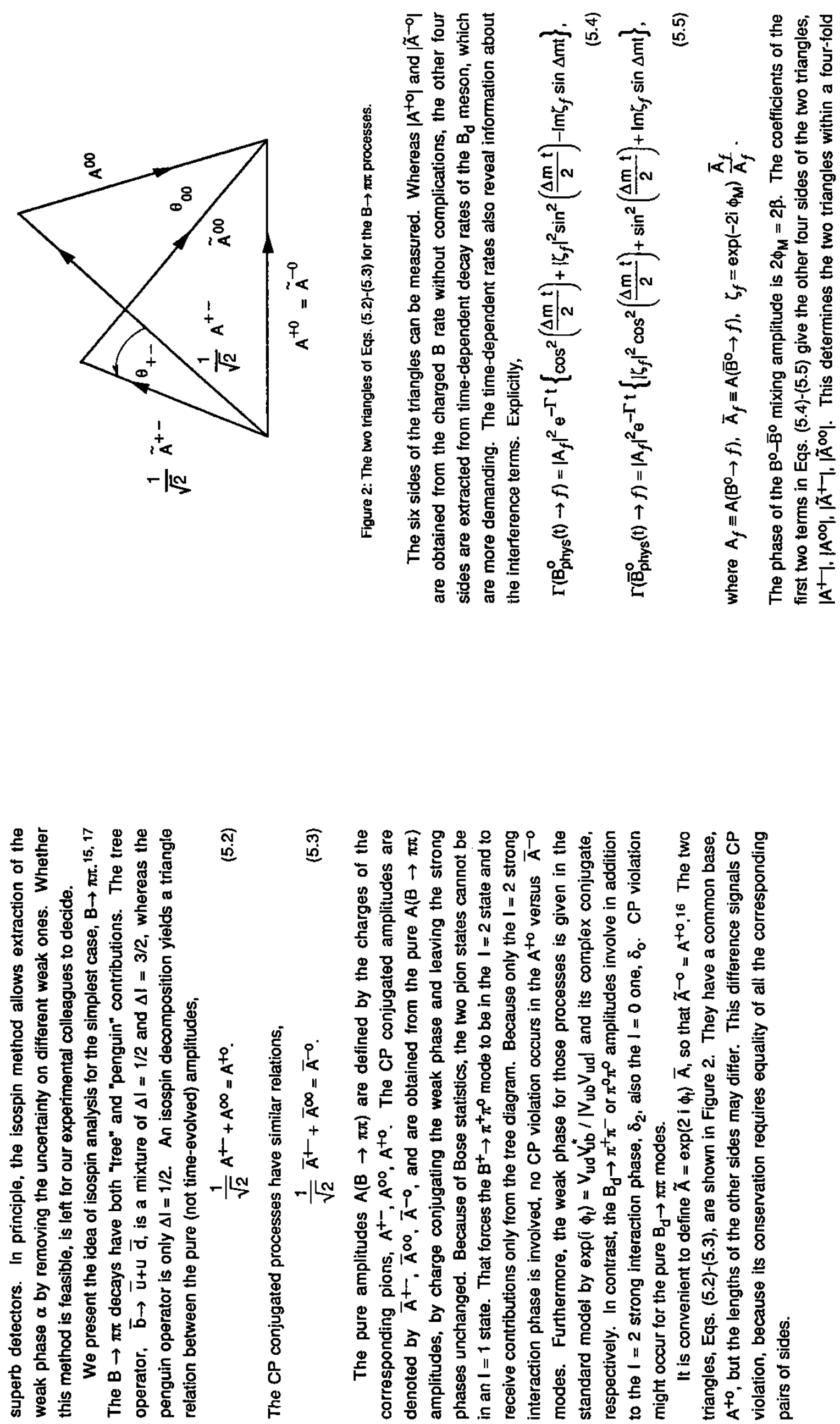


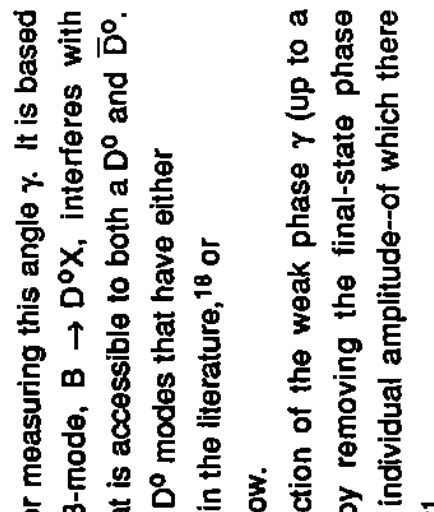

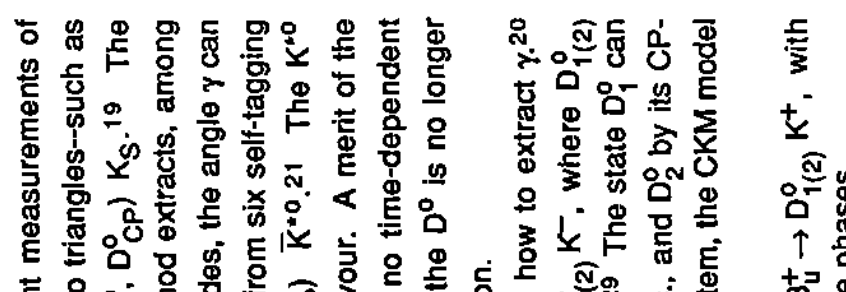

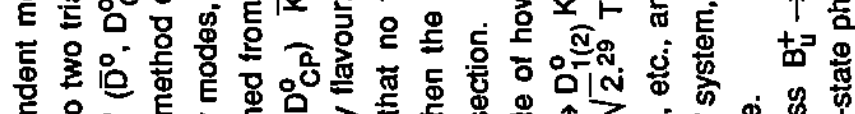

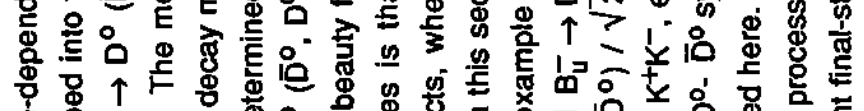

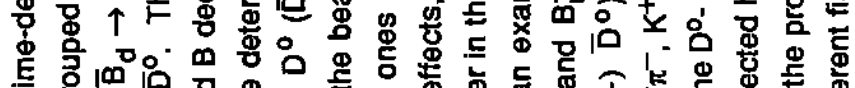

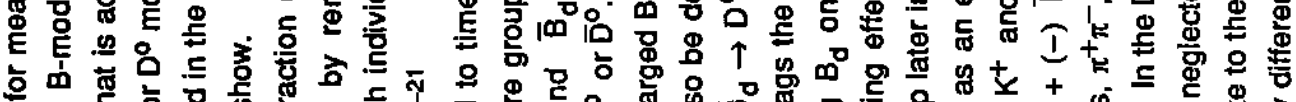

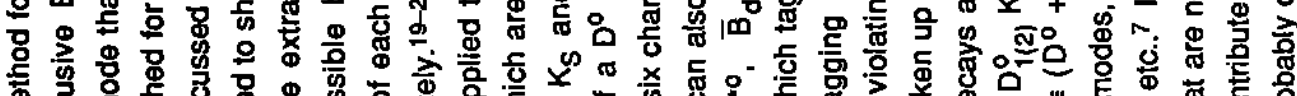

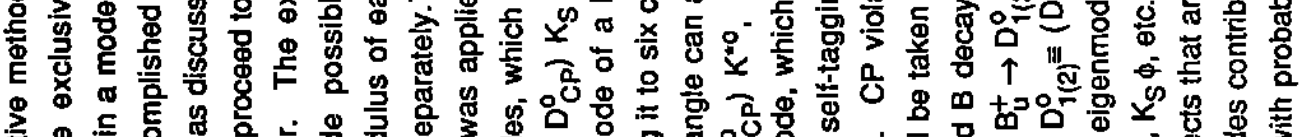

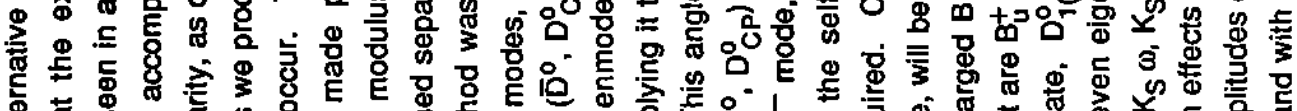

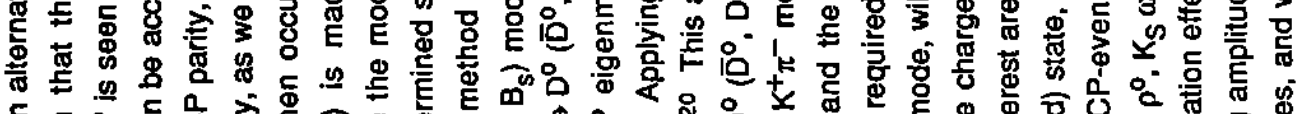
ᄃ

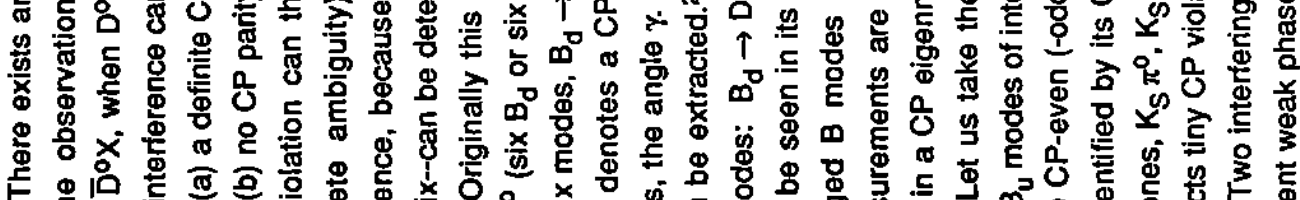

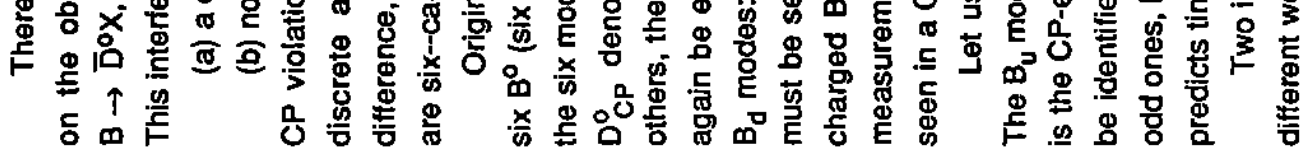
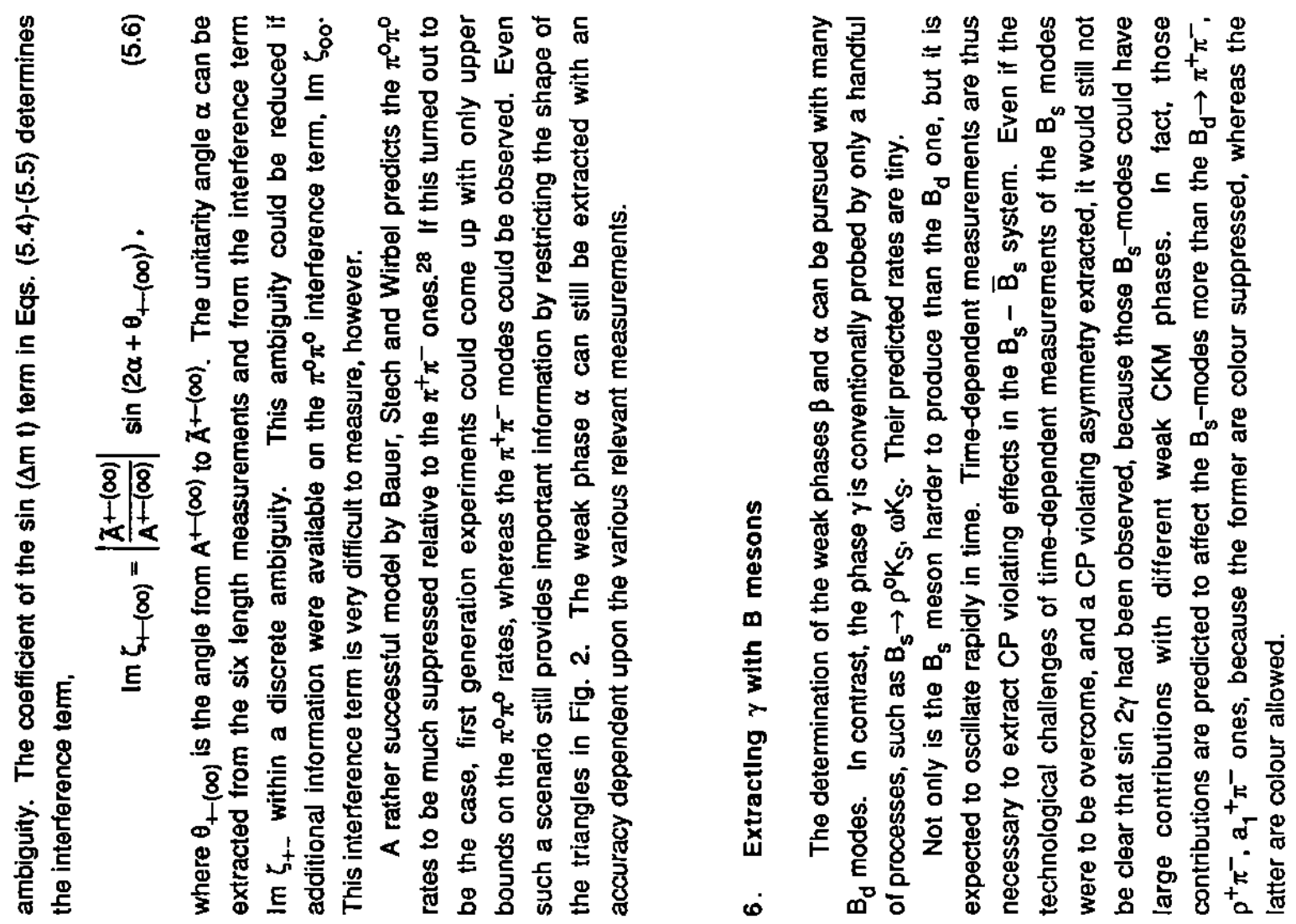

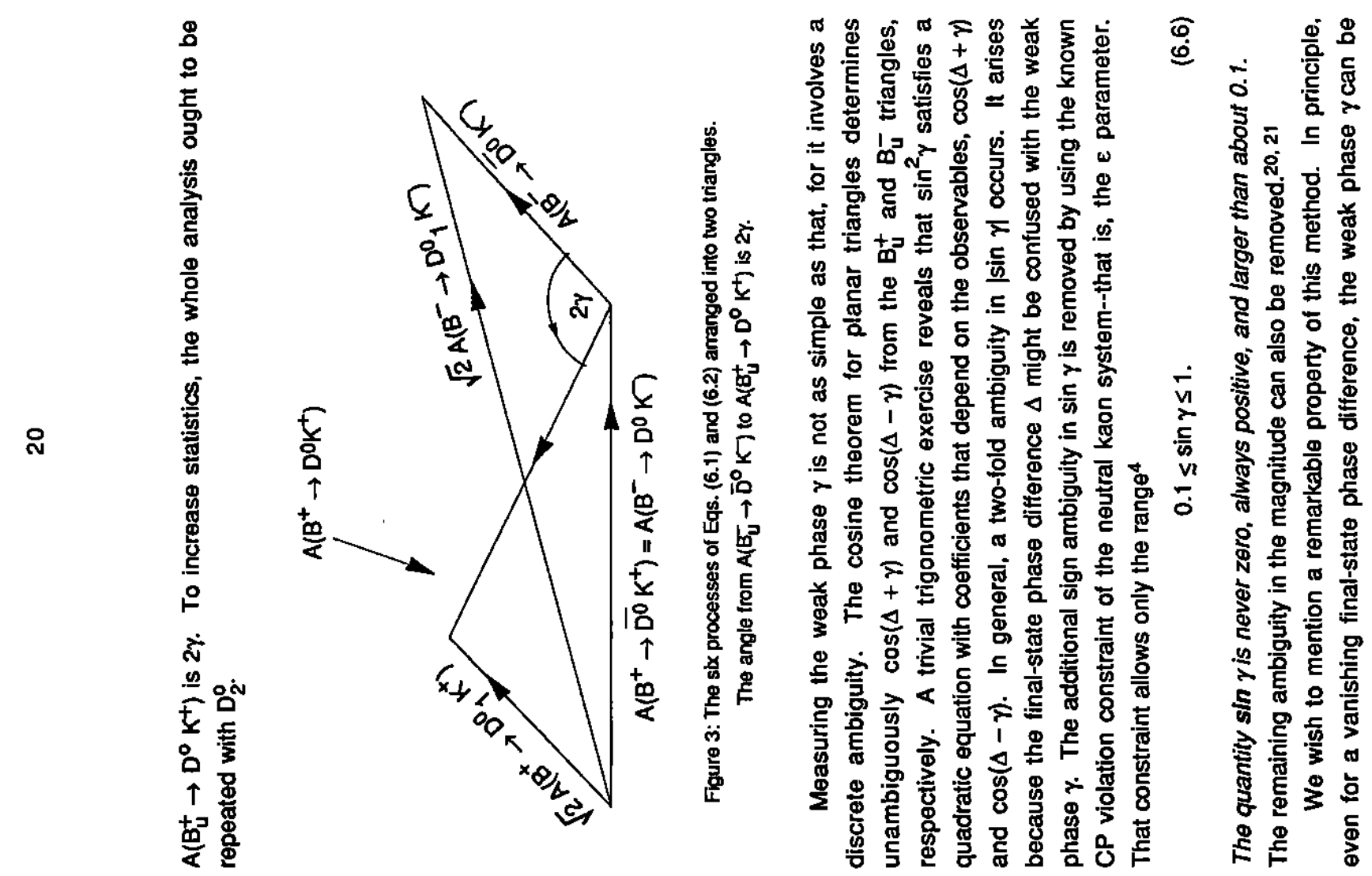

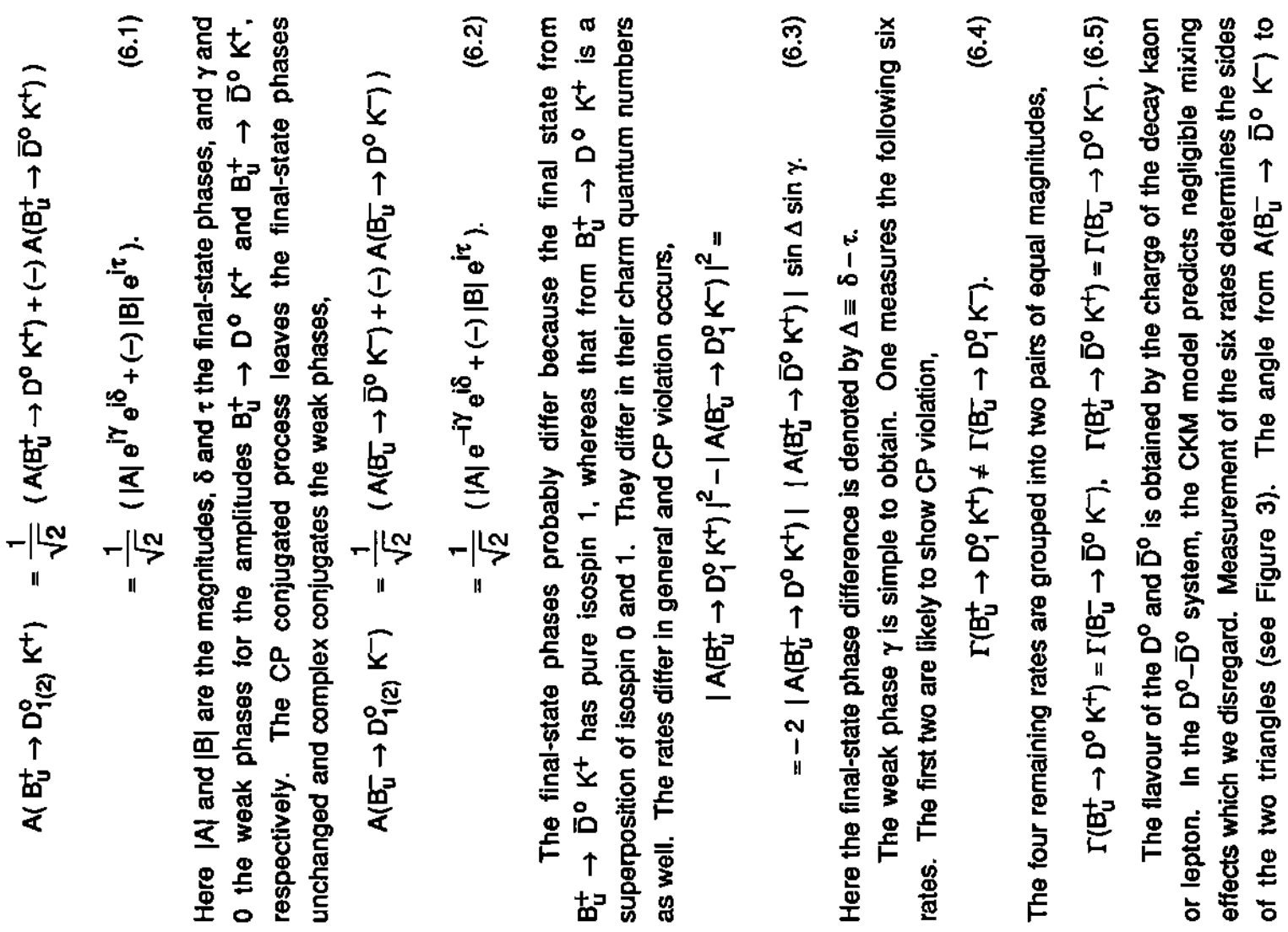



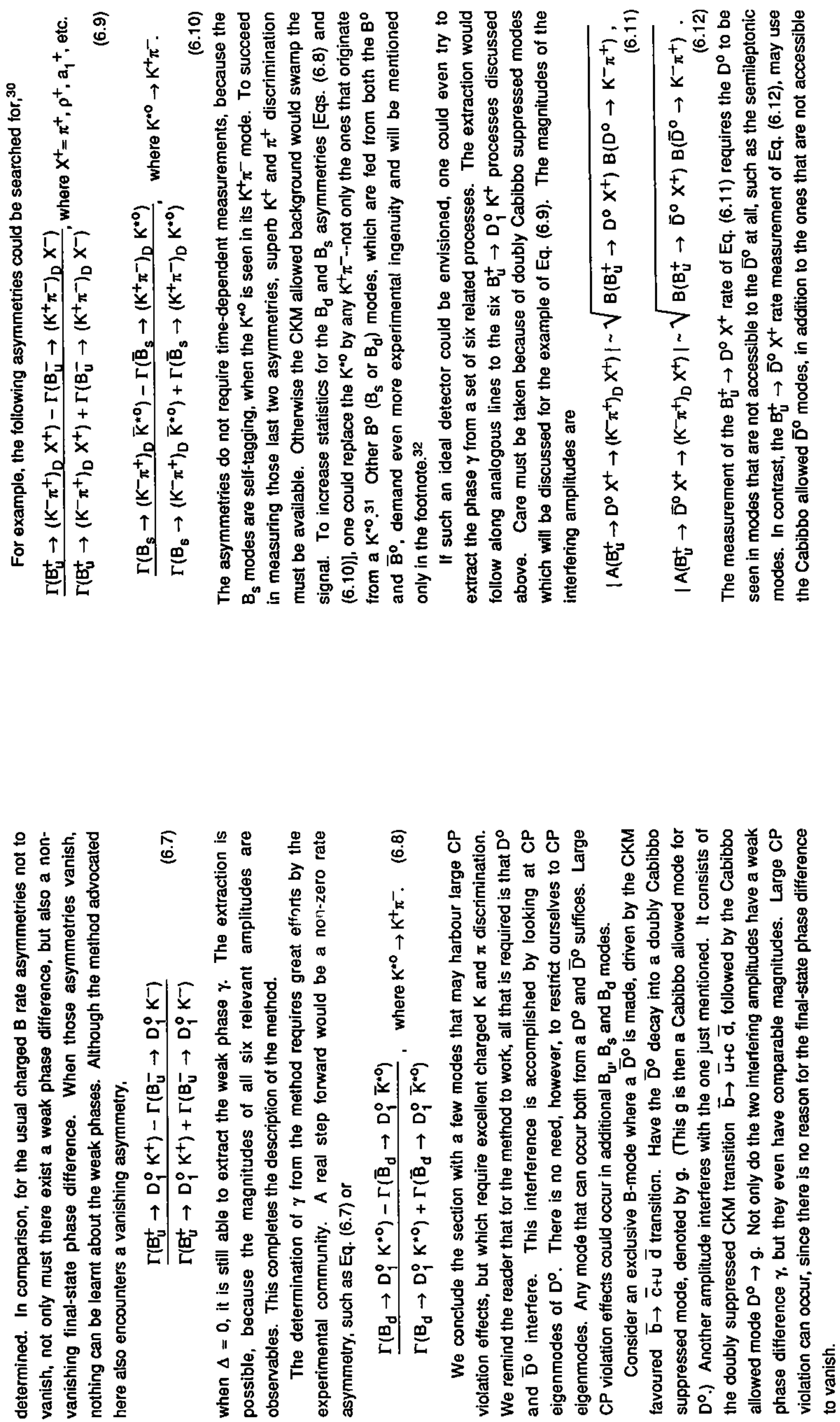
IMIm (I) III II IEI I) 1) 8

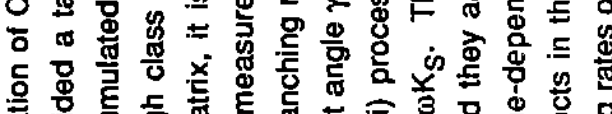

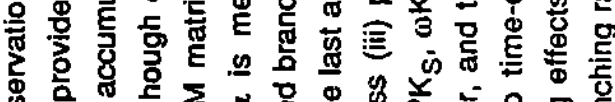

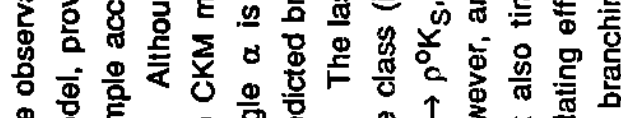

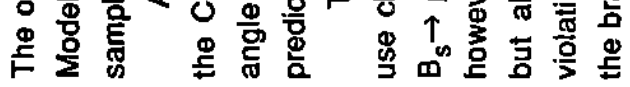

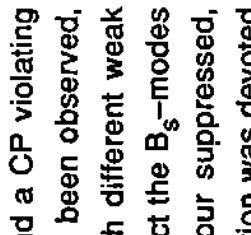

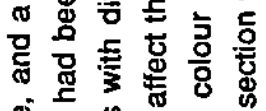

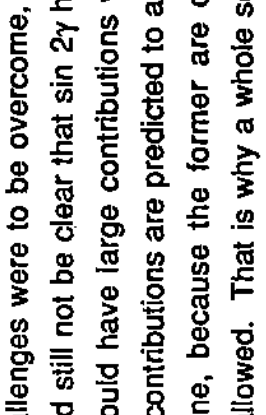

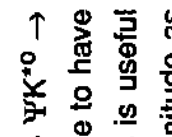
$\uparrow$ क 兽茄

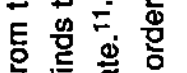
ᄃ

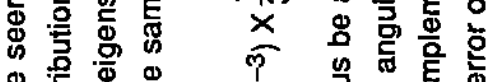

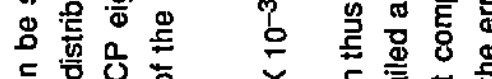

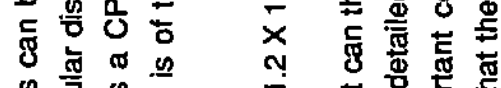

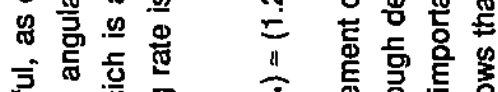
흥 올 要

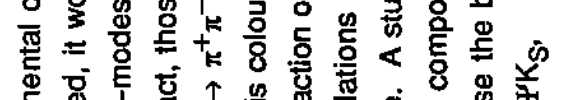

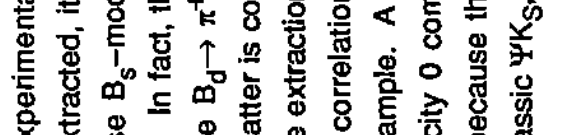

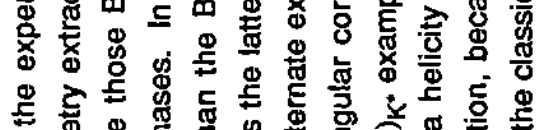

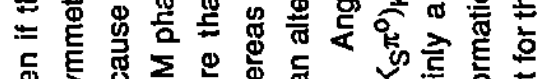

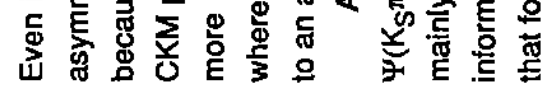

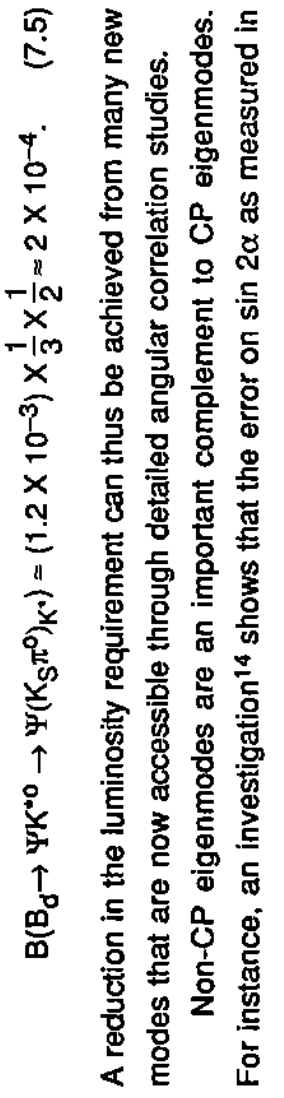

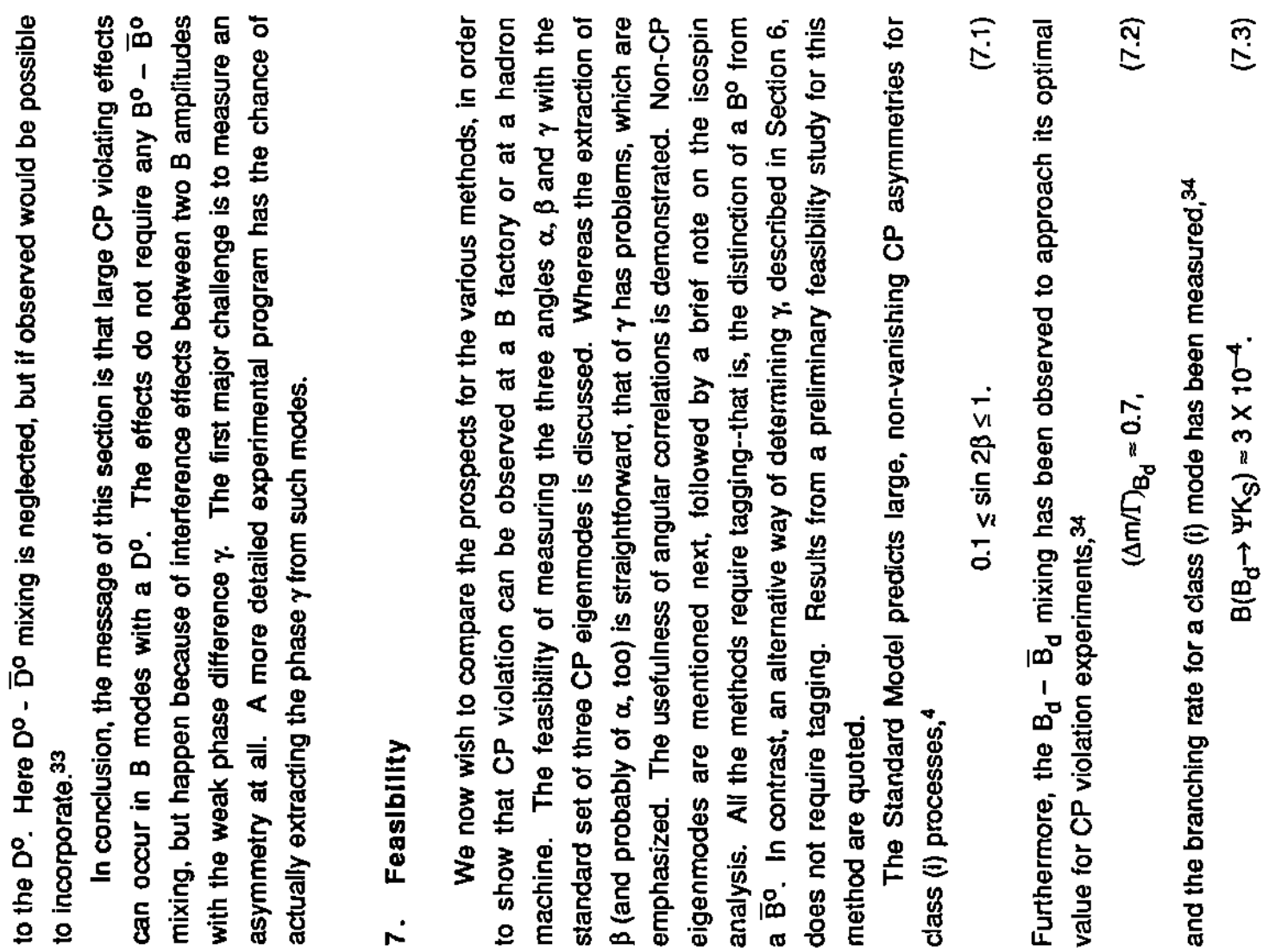



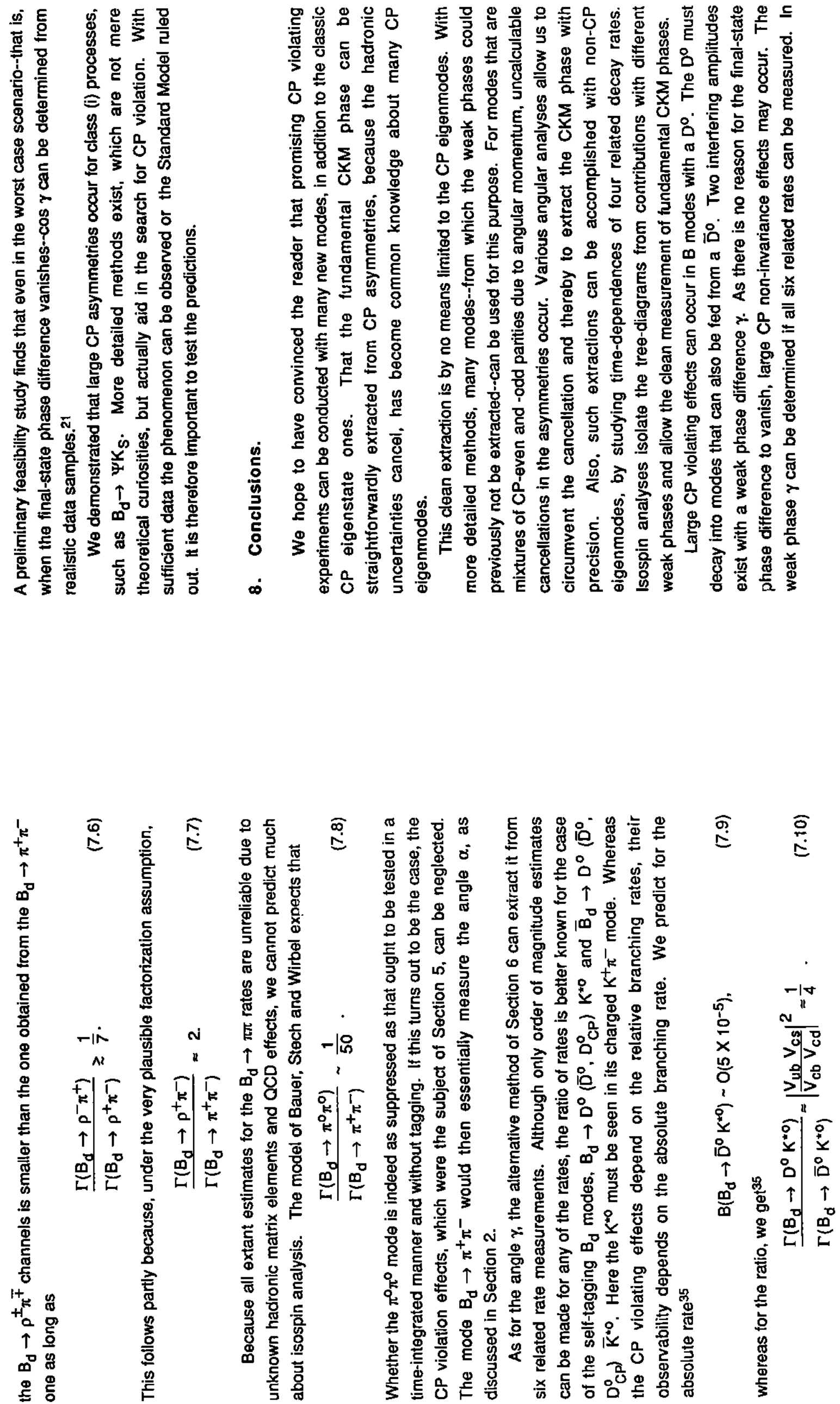
ஸ

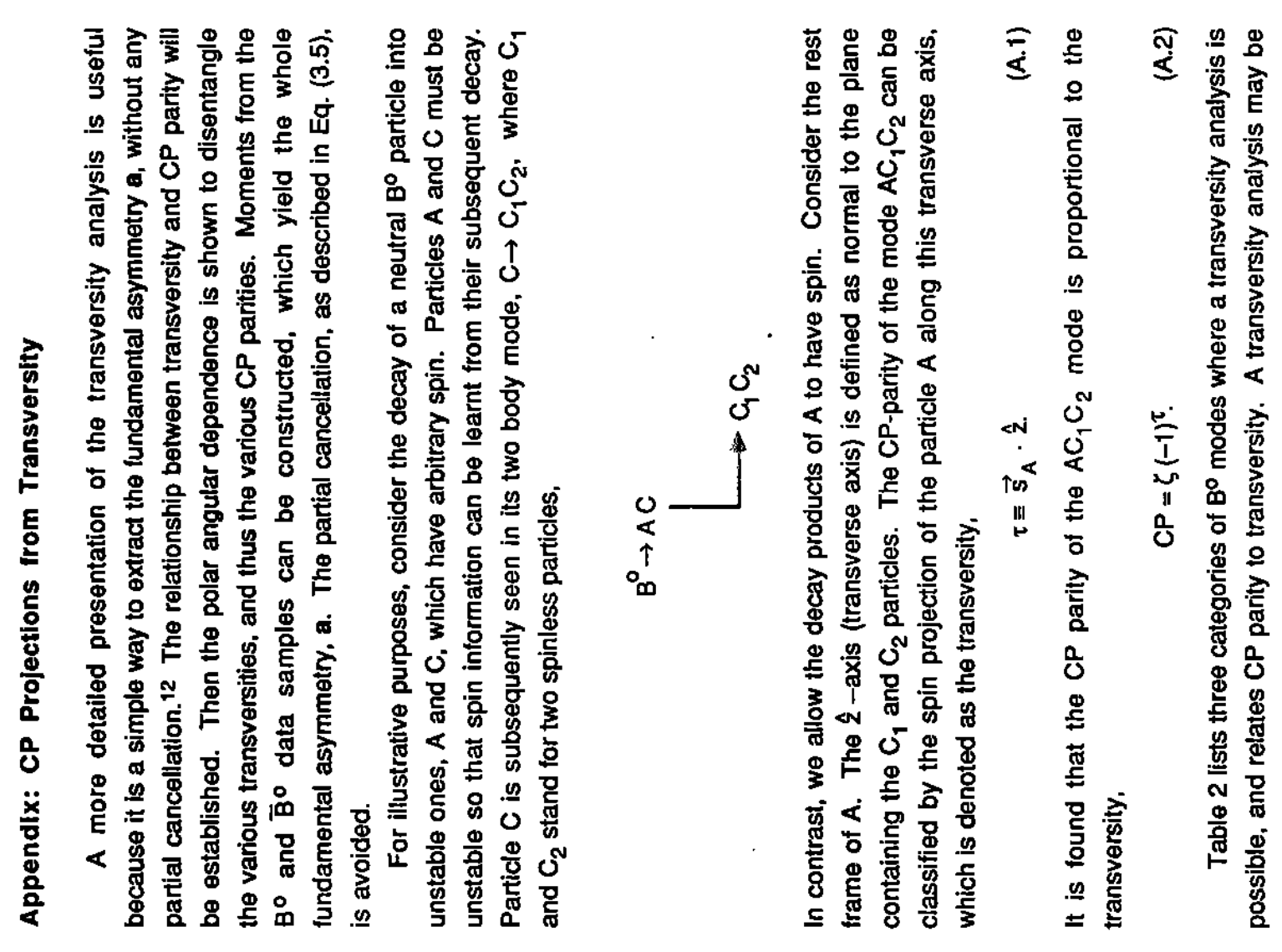

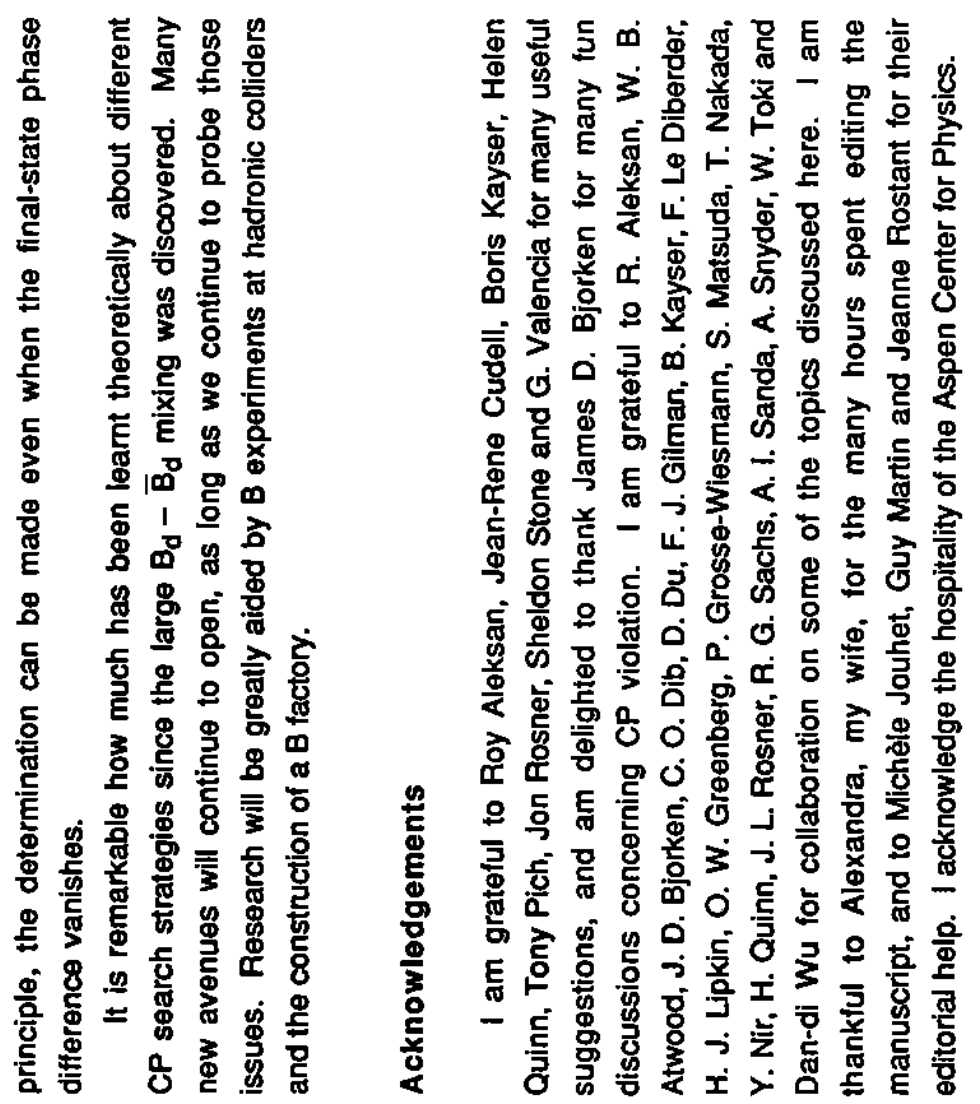



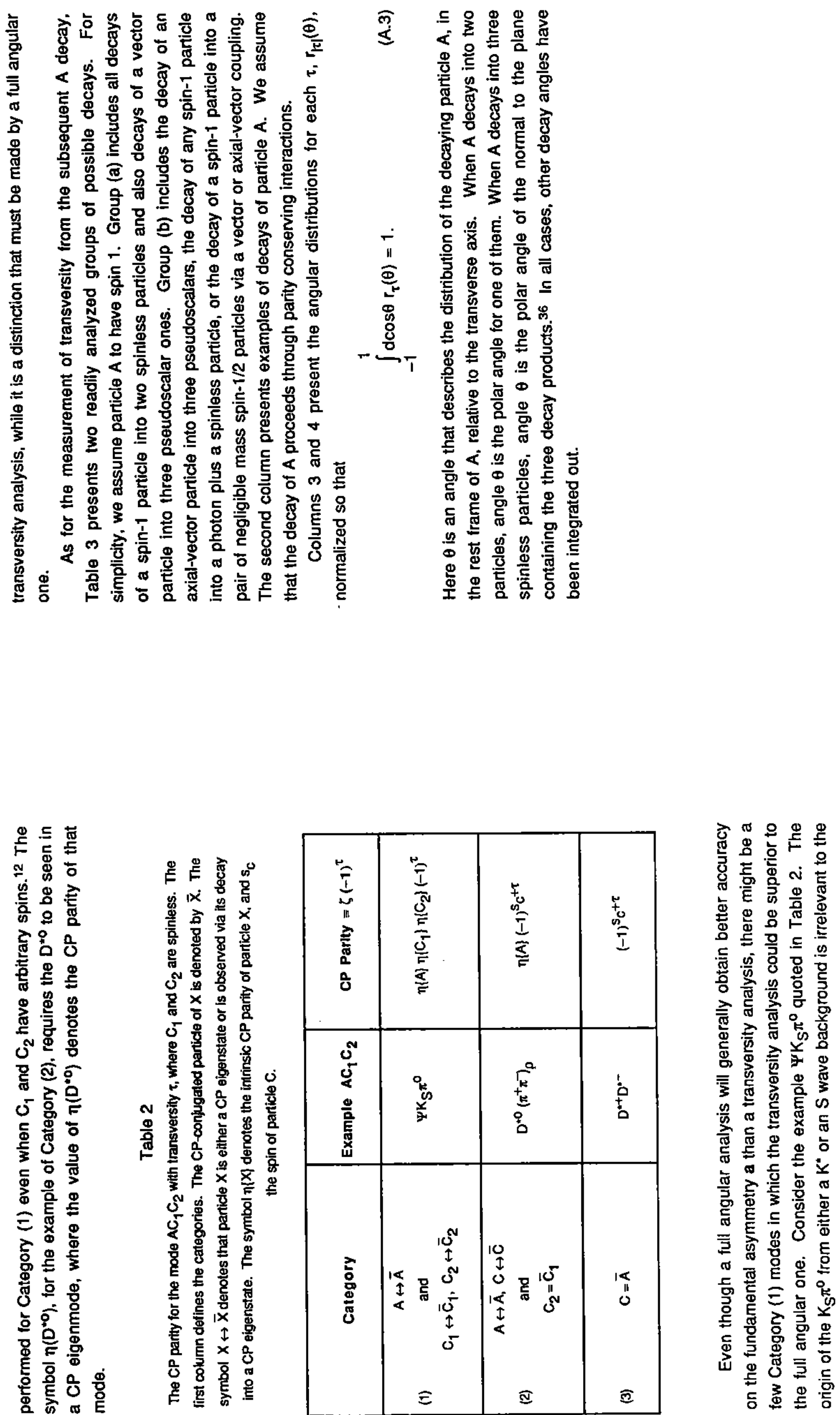

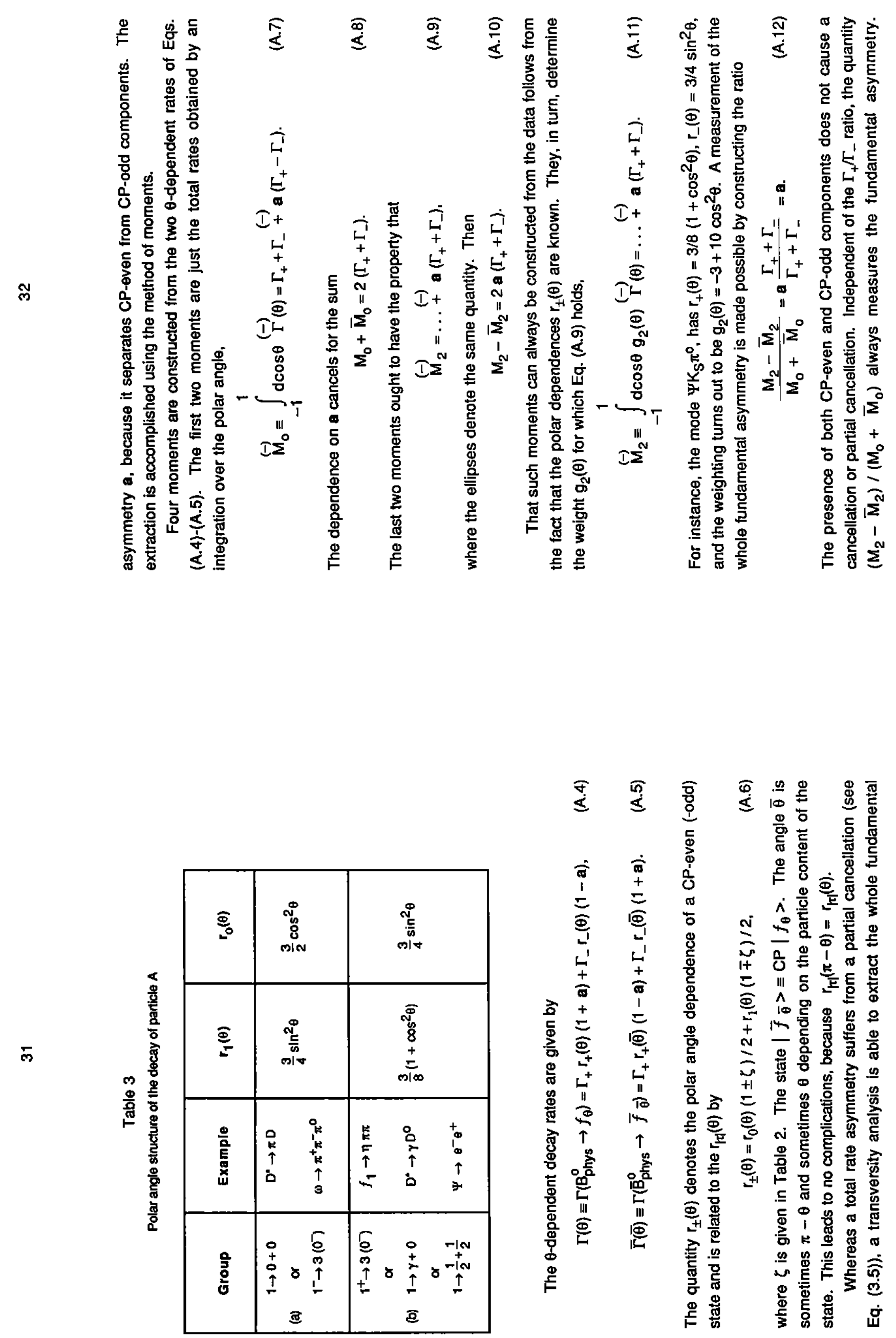

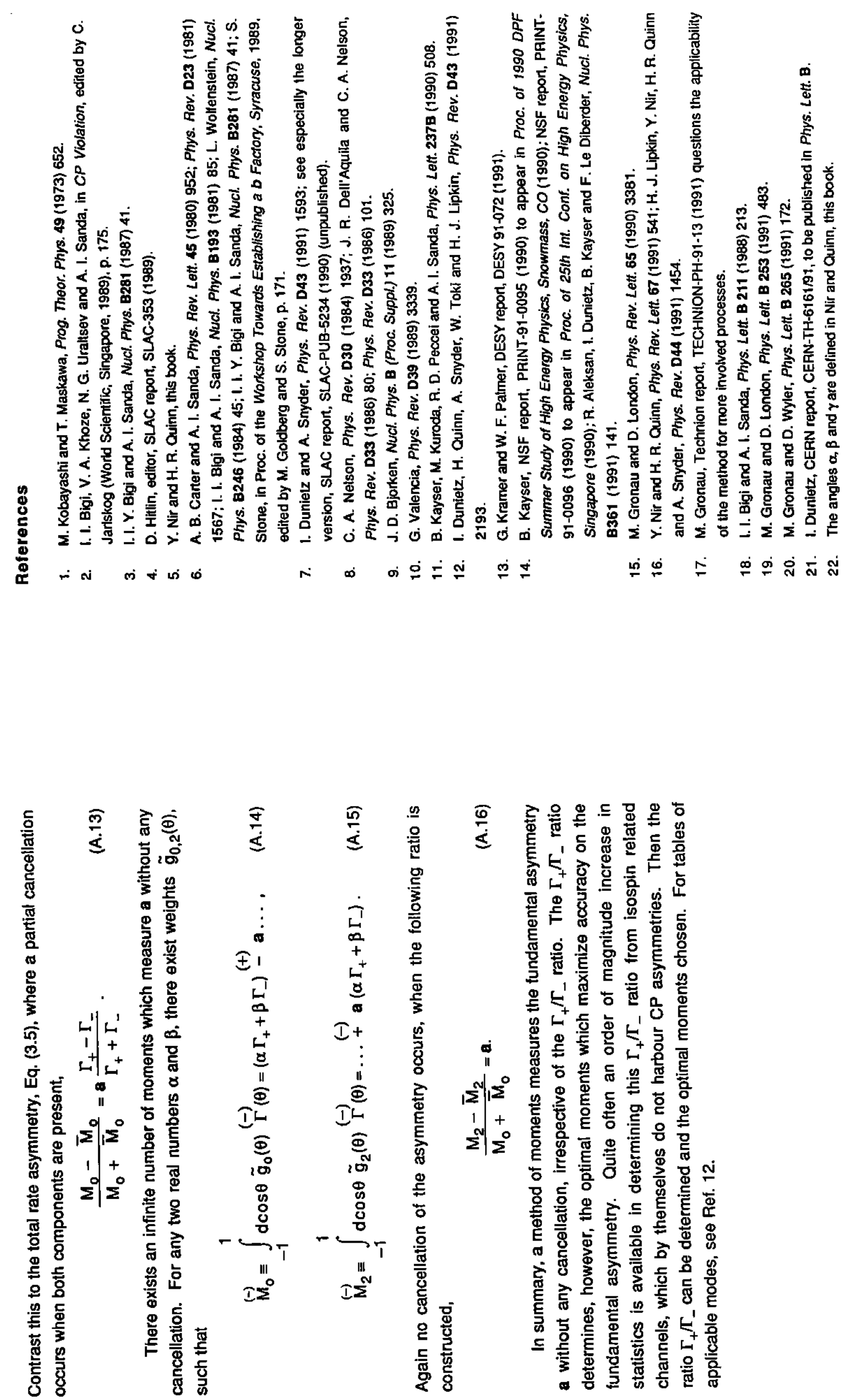


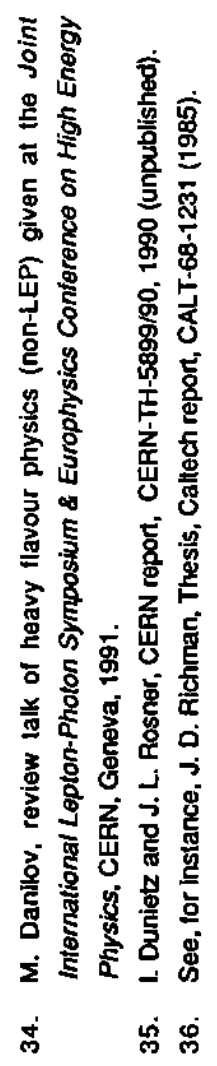

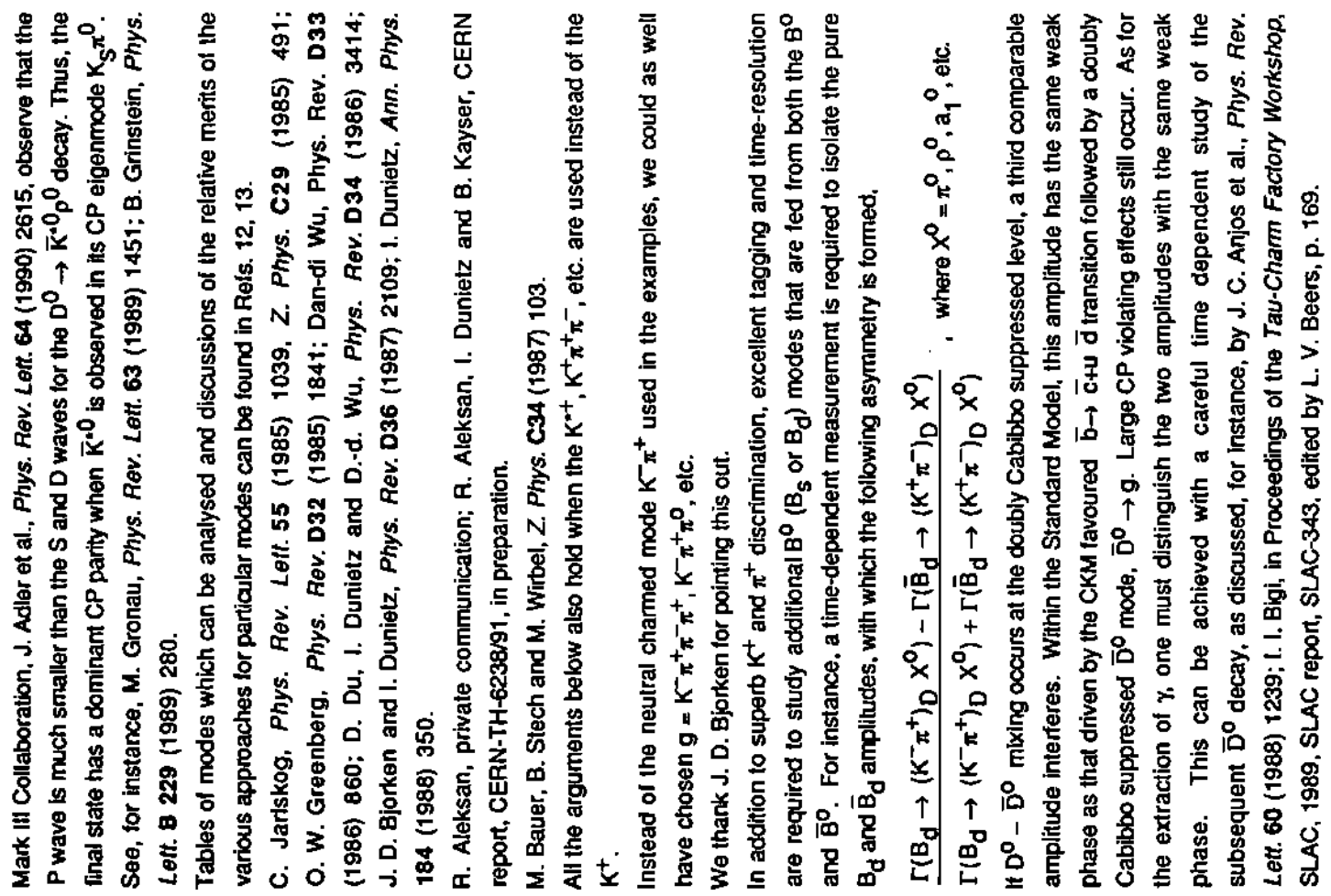

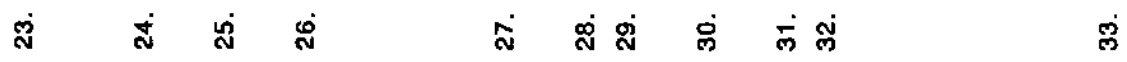

